V.V. Rymsha, I.N. Radimov, M.V. Gulyy, I.V. Merkulov

\title{
MOTORSOLVE SOFTWARE PACKAGE: VERIFICATION OF PARAMETERS AND CHARACTERISTICS OF THE BRUSHLESS PERMANENT MAGNET MOTOR
}

\begin{abstract}
Purpose. The purpose of this paper is to include comparison of results of the modeling and calculation in the Mentor Siemens software MotorSolve and experiment of the brushless permanent magnet motor. Methodology. Numerical investigation using licensed software MotorSolve is performed. Calculations of motor parameters and characteristics are made using Finite Element Method. The experimental investigations were made on the hysteresis dynamometer AHD-603. Results. The results of the investigations show that the calculations of the parameters and characteristics of the motor in MotorSolve software almost match with the results of the experiments. Practical value. The high efficiency of the MotorSolve software for the modeling, calculation and research of the brushless permanent magnet motors are confirmed. References 4, tables 2, figures 10.

Key words: brushless permanent magnet motor, stator winding data, experimental investigations.
\end{abstract}

Розглянуто деякі можливості програмного комплексу МоtorSolve для моделювання $і$ аналізу вентильних двигунів 3 постійними магнітами. Наведено результати розрахунку параметрів і характеристик вентильного двигуна 3 відомими геометричними розмірами і даними обмотки статора. Результати розрахунку зіставлені з результатами експериментальних досліджень. Бібл. 4, табл. 2, рис. 10.

Ключові слова: вентильний двигун 3 постійними магнітами, обмоткові дані статора, експериментальні дослідження.

Рассмотрены некоторые возможности программного комплекса MotorSolve для моделирования и анализа вентильных двигателей с постоянными магнитами. Представлены результаты расчета параметров и характеристик вентильного двигателя с известными геометрическими размерами и обмоточными данными статора. Результаты расчета сопоставлены с результатами экспериментальных исследований. Библ. 4, табл. 2, рис. 10.

Ключевые слова: вентильный двигатель с постоянными магнитами, обмоточные данные статора, экспериментальные исследования.

Introduction. One of the advanced computer systems for the design and analysis of electric machines is the Mentor Siemens MotorSolve system, which is a software package that allows to simulate and calculate the parameters and characteristics of various types of electric machines [1]. The use of the MotorSolve system significantly speeds up the design process due to the availability of ready-made templates of designs for stators and rotors of induction machines, DC collector machines, and brushless permanent magnet machines, as well as an extensive library of materials used in electric machines.

Modeling an electric machine in the MotorSolve code, as well as determining its parameters and characteristics, is based on a circuit-field model. Magnetic field of the machine is calculated by the Finite Element Method, as well as in the well-known FEMM code. However, the FEMM code is not suitable for the direct calculation of the parameters and characteristics of the designed electrical machines without additional calculations outside the software.

Currently, brushless permanent magnet motors (BPMM) are a popular type of electric machine for special applications. There are a number of publications devoted to theoretical studies of BPMM in the MotorSolve software package, for example [2, 3]. However, there are very few publications devoted to verifying the calculation results of such machines in MotorSolve with the experimental results, and these are mainly scattered materials on the Internet. Verification is also of interest because the models and algorithms embedded in the MotorSolve code are closed to the user, which makes it impossible to assess the accuracy of the results obtained in the calculation.
In this regard, the goal of the paper is to compare the calculation results in the licensed software package MotorSolve of a BPMM which has known geometric dimensions and winding data with the experimental results.

Object of study. The object of the study is the BPMM, which was designed at «Electrical Engineering New Technology» Ltd (Odessa) and is currently massproduced (Fig. 1)

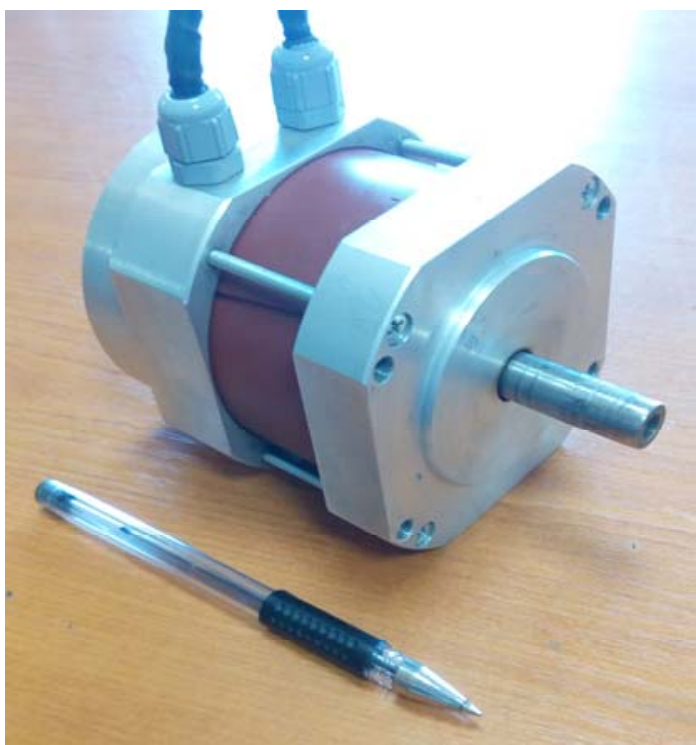

Fig. 1. External view of BPMM

For operation from a single-phase AC network $220 \mathrm{~V} 50 \mathrm{~Hz}, \mathrm{BPMM}$ is equipped with a rotor position sensor and an electronic converter, which is a controllable

(C) V.V. Rymsha, I.N. Radimov, M.V. Gulyy, I.V. Merkulov 
electronic switch and a rectifier device. The electronic switch according to the signals of the rotor position sensor provides BPMM operation in the mode of a brushless DC motor with 120-degree phase switching.

The geometric dimensions of the active part of the studied BPMM and its winding data are given in Table 1.

\begin{tabular}{|l|c|}
\multicolumn{1}{|c|}{ BPMM geometric dimensions and winding data } \\
\hline \multicolumn{1}{|c|}{ Name } & Value \\
\hline Outer stator diameter, $\mathrm{mm}$ & 82 \\
\hline Inner stator diameter, $\mathrm{mm}$ & 50 \\
\hline Number of phases $m$ & 3 \\
\hline Number of stator slots $Z$ & 12 \\
\hline Number of rotor poles $2 P$ & 10 \\
\hline Gap between stator and rotor, mm & 0,25 \\
\hline Stator package length, mm & 42 \\
\hline Magnet height, mm & 2,5 \\
\hline Magnet width, mm & 12 \\
\hline Brand of magnet & $\mathrm{N} 38 \mathrm{SH}$ \\
\hline Winding connection circuit & $\mathrm{Y}$ \\
\hline Number of turns in the coil & 80 \\
\hline Wire diameter, mm & 0,5 \\
\hline
\end{tabular}

Creating a model of BPMM in the MotorSolve software package. Figure 2 shows the cross section of the active part of the studied BPMM obtained in the MotorSolve software package.

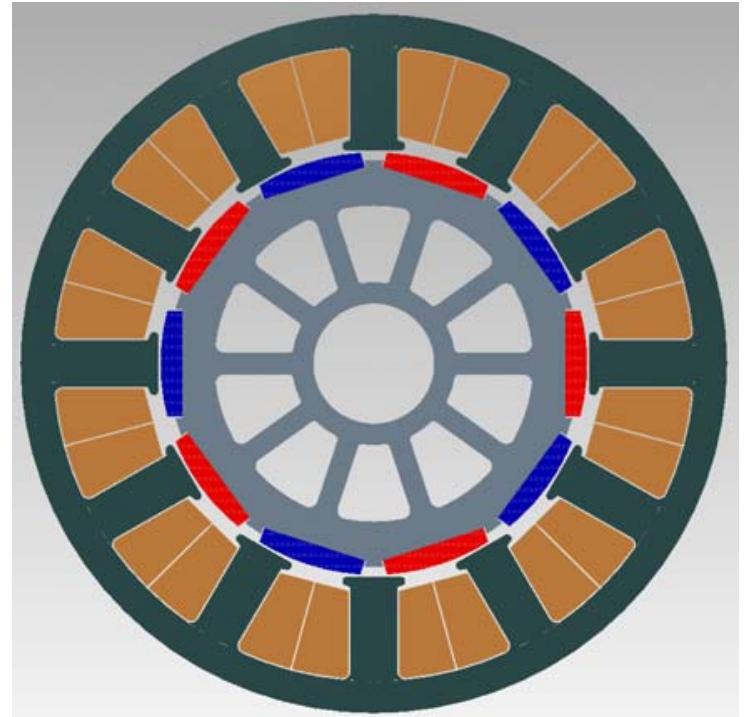

Fig. 2. Cross section of the BPMM active part

To reduce the mass and moment of inertia, the BPMM rotor is made in the form of a wheel with spokes and a low yoke height. The BPMM stator has open slots and a winding with a fractional number of slots per pole and phase: $q=\frac{Z}{2 p \cdot m}=\frac{12}{10 \cdot 3}=\frac{2}{5}$. Pole division: $\tau=m \cdot q=3 \cdot \frac{2}{5}=1 \frac{1}{5}$. Then the step of the winding is 1 and each of the coils covers one tooth. In this case, the stator coil winding has short frontal parts, which improves the temperature regime of the winding and, in addition, reduces the possibility of its breakdown due to the lack of phase overlap in the area of the frontal parts. The stator winding diagram is shown in Fig. 3.

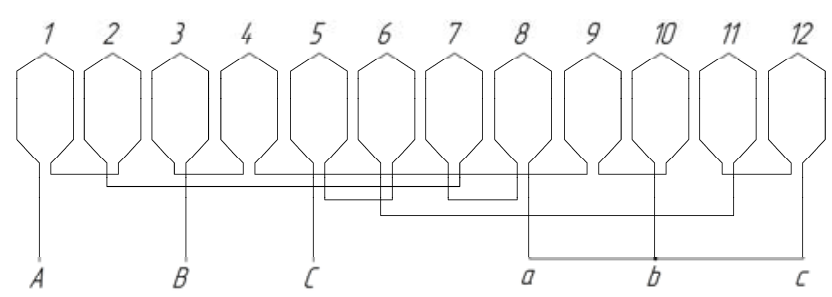

Fig. 3. BPMM stator winding diagram

The initial data for the procedure for forming a winding in the MotorSolve code are its type and connection circuit, wire diameter, number of parallel branches and the number of turns in the coil of the winding.

After setting the geometric dimensions, selecting active and structural materials, as well as forming the winding, the code allows to visualize the magnetic field in the form of lines of force for the selected position of the motor's rotor (Fig. 4).

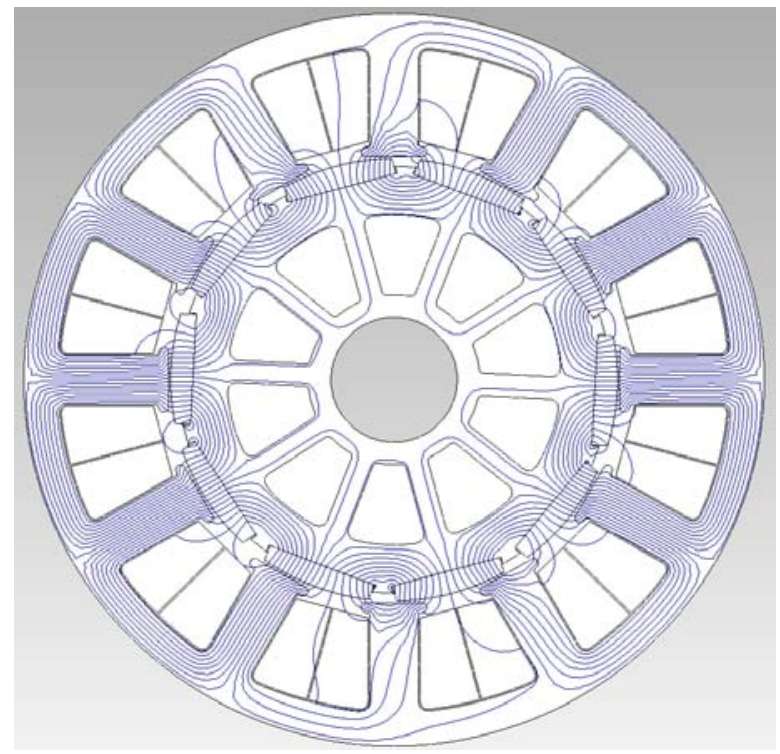

Fig. 4. BPMM magnetic field lines

Analysis of the distribution of the magnetic field of the motor allows to check the model of BPMM for the absence of errors in its formation. Figure 4 shows that the distribution of the magnetic field corresponds to the physics of the process occurring in electric machines.

After creating the BPMM model, the MotorSolve code calculates the masses of active materials and the total mass of the motor, the resistance of its winding, the moment of inertia of the rotor, as well as a number of other quantities.

Among the calculation results there is a recommendation on the advisability of skewing the stator magnetic core to eliminate cogging torque. For the considered BPMM, a skew of the stator magnetic core is recommended at an angle of 0.2 tooth divisions or at 6 mechanical degrees (30 electrical degrees). It should be noted here that the same skew value was determined on the basis of field calculations in the FEMM code when designing a serial BPMM and was incorporated into the 
design documentation for the electric motor. As practice has shown, in serially produced electric motors, the cogging torque is practically absent.

Verification of parameters, design constants and characteristics of BPMM. The results of calculating the parameters and constants of the studied BPMM in the MotorSolve code are presented in Fig. 5.

\begin{tabular}{|l|l|}
\hline & Prototype Design \\
\hline Ke (peak line-line Back-EMF over speed) $(\mathbf{V} / \mathbf{k r p m})$ & 116 \\
\hline Kt (derived from $\mathrm{Ke})(\mathbf{N} \cdot \mathbf{m} / \mathbf{A})$ & 1.36 \\
\hline Ld $(\mathbf{d}$-axis inductance) $(\mathbf{m H})$ & 6.55 \\
\hline Lq (q-axis inductance) $(\mathbf{m H})$ & 8.76 \\
\hline Lllmin (minimum line-line inductance) $(\mathbf{m H})$ & 13.1 \\
\hline Lllmax (maximum line-line inductance) $(\mathbf{m H})$ & 17.5 \\
\hline Rs (stator phase resistance) $(\boldsymbol{\Omega})$ & 3.27 \\
\hline Rll (stator line-line resistance) $(\mathbf{\Omega})$ & 6.54 \\
\hline Phi_m (magnet d-axis flux linkage) $(\mathbf{W b})$ & 0.123 \\
\hline
\end{tabular}

Fig. 5. MotorSolve code output after BPMM parameters calculation

It is advisable to begin verifying the BPMM parameters with inductances, the values of which are necessary in the calculations of transients, the electromagnetic time constant, and the reactive component of the electromagnetic torque.

In Fig. 5: $L l l_{\min }$ (minimum line-line inductance) is the stator winding inductance along the longitudinal $(d)$ axis, and $L l l_{\max }$ (maximum line-line inductance) is the stator winding inductance along the transverse $(q)$ axis. The values of these inductances are twice as large as the values of the inductances of the stator winding phase, indicated in Fig. 5 as $L_{d}$ and $L_{q}$ respectively $\left(L l l_{\min }=2 \cdot L_{d}, L l l_{\max }=2 \cdot L_{d q}\right)$.

Let us compare the calculation results with experimental data. The inductances of the serial BPMM were measured using the DCR-9935 LCR-meter and a mechanical device that allows the motor shaft to be rotated by a predetermined angle. The results of comparing inductances are summarized in Table 2.

Table 2

BPMM inductances

\begin{tabular}{|c|c|c|}
\hline Value & Calculation & Experiment \\
\hline$L l l_{\min }, \mathrm{mH}$ & 13,1 & 13,8 \\
\hline$L l_{\max }, \mathrm{mH}$ & 17,5 & 18,1 \\
\hline
\end{tabular}

Table 2 shows that the results of calculation and experiment have good convergence. In addition, as is known, a feature of BPMM (unlike synchronous motors with electromagnetic excitation) is that the stator winding inductance along the $d$ axis is smaller than the stator winding inductance along the $q$ axis, which is confirmed by the data in Fig. 5 and Table 2 .

Consider the correspondence between the calculated and experimental data of the flux linkage of the stator winding of the motor, the value of which is included in the equation for calculating the active (main) component of the electromagnetic torque of BPMM [4]. As a result of calculation in MotorSolve, the value of the flux linkage of the phase of the winding is obtained at its orientation along the $d$ axis (Phi_m in Fig. 5) $\Psi_{f}=0.123 \mathrm{~Wb}$. In this case, there is a maximum linkage of the winding phase with the flux created by the permanent magnets of the rotor. When the winding is connected according to the «Y» circuit, two winding phases connected in series are shifted in the magnetic field of the permanent magnets by an angle of 60 electrical degrees. In this case, the value of the flux linkage of the winding is greater than the flux linkage of the phase at $\sqrt{3}$ time, i.e. $\Psi_{M S}=\sqrt{3} \Psi_{f}=$ $=0.213 \mathrm{~Wb}$.

To experimentally determine the flux linkage of the stator winding, the rotor of the serial BPMM is rotated at a constant speed from the racing electric motor (generator mode without connecting the load). Using the ADDS1062CM digital oscilloscope, an oscillogram of the change in the linear EMF of the BPMM stator winding in time $e=f(t)$ is recorded (Fig. 6).

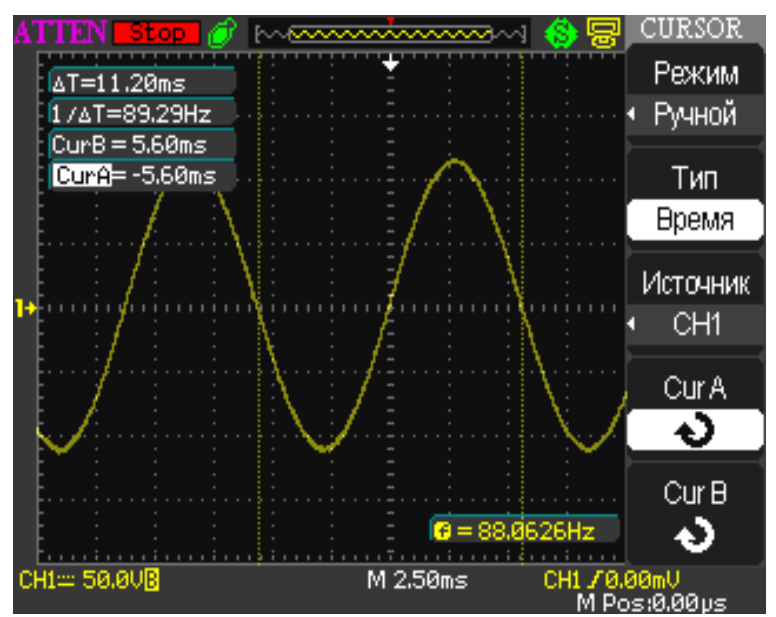

Fig. 6. Experimental oscillogram $e=f(t)$

Scale on the oscillogram: vertical - $50 \mathrm{~V} /$ div., horizontal $-2.5 \mathrm{~ms} / \mathrm{div}$.

As can be seen from Fig. 6, the linear EMF has a shape close to sinusoidal. Based on the presented experimental oscillogram, we calculate the flux linkage of the BPMM stator winding:

$$
\Psi_{\mathrm{E}}=\frac{E_{\mathrm{max}} \cdot \Delta T}{2 \pi}=\frac{118,5 \cdot 10^{-3}}{2 \pi}=0,211 \mathrm{~Wb},
$$

where $E_{\max }$ is the amplitude EMF value; $\Delta T$ is the EMF change period.

Thus, a practical coincidence with the result of calculating the stator winding flux linkage obtained in the MotorSolve software package $\Psi_{M S}=0.213 \mathrm{~Wb}$ is confirmed.

Knowing the flux linkage, it is possible to determine the constant of EMF of the electric motor $K_{e}$ and the constant of the torque of the electric motor $K_{t}$. These constants characterize the electromechanical conversion of energy in electrical machines. They are numerically equal to each other when applying a single system of units.

The constant of EMF $K_{e}$ is equal to the product of the number of pole pairs $p$ and flux linkage of the stator winding. According to the experiment, the constant $K_{e}$ when calculating through flux linkage:

$$
K_{e}=p \cdot \Psi_{\mathrm{E}}=5 \cdot 0,211=1,055 \mathrm{~V} \cdot \mathrm{s},
$$

and obtained in the MotorSolve code 


$$
K_{e}=p \cdot \Psi_{M S}=5 \cdot 0,213=1,065 \mathrm{~V} \cdot \mathrm{s} .
$$

On the other hand, according to Fig. 5, the constant $K_{e}=116 \mathrm{~V} / 1000 \mathrm{~min}^{-1}$, or $K_{e}=116 \cdot \frac{9,55}{1000}=1,107 \mathrm{~V} \cdot \mathrm{s}$.

Thus, the discrepancy between the constant of EMF $K_{e}$ obtained in two ways based on the calculated data of MotorSolve shown in Fig. 5 is $3.9 \%$. This difference is most likely due to the calculation error in the MotorSolve of EMF obtained by differentiating the stator winding flux linkage. Unfortunately, the MotorSolve code does not have the ability to evaluate the degree to which the stator winding flux linkage matches the sine waveform.

The torque constant $K_{t}$, numerically equal to the constant of EMF $K_{e}$, which is calculated through the flux linkage of the winding from the MotorSolve code, is $K_{t}=1.065 \mathrm{~N} \cdot \mathrm{m} / \mathrm{A}$.

As for the torque constant $K_{t}=1.36 \mathrm{~N} \cdot \mathrm{m} / \mathrm{A}$ shown in Fig. 5, it is determined artificially from the constant of EMF $K_{e}$ by dividing by $K_{e}$, and therefore is not a parameter of BPMM. At the same time, the above other parameters obtained by calculation in the MotorSolve program have good agreement with the experiment.

It is of interest to compare the calculated and experimental mechanical characteristics of the studied BPMM, as well as the change in the motor current in time at a given load on the shaft. The mechanical characteristics were experimentally determined on a bench with the AHD-603 hysteresis dynamometer, with which the BPMM was loaded (Fig. 7).

The calculations and experimental determination of the characteristics were carried out at a constant («smooth») voltage in the DC link of the $270 \mathrm{~V}$ electronic switch to exclude the influence of the rectification circuit on the characteristics of BPMM. Figure 8 shows the calculated (in MotorSolve) and experimental «natural» mechanical characteristics of the studied BPMM obtained when the motor was running without speed control (filling the PWM signal is 1).

The presented mechanical characteristics show acceptable convergence of the calculation with the experiment. The idle rotation speed of the calculated characteristic is less than the experimental idle rotation speed by $3.3 \%$. At the same time, the stiffness of the calculated mechanical characteristic is slightly greater than the rigidity of the experimental mechanical characteristic.

Figures 9, 10 show the calculated and experimental oscillograms of the phase current of BPMM during its operation with the opposing load torque on the shaft of $1 \mathrm{~N} \cdot \mathrm{m}$.

The calculated characteristic was determined at a rotational speed of $2270 \mathrm{rpm}$. The average current value was $1.04 \mathrm{~A}$.

Comparison of the oscillograms in Fig. 9, 10 allows to conclude that the calculated and experimental values of the currents correspond to physical representations of transients during switching of the phases of the stator winding, are correlated in shape and amplitude, and also once again confirm the adequacy of the calculation of the BPMM parameters in the MotorSolve software package.

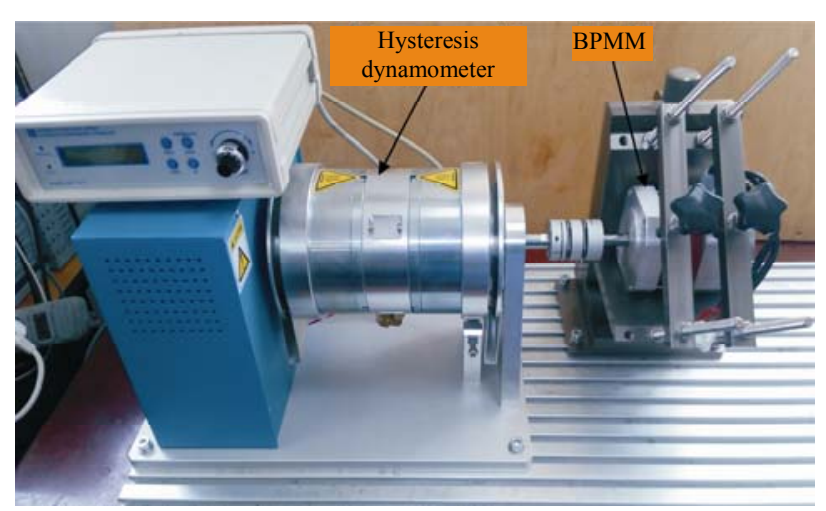

Fig. 7. General view of the experimental bench

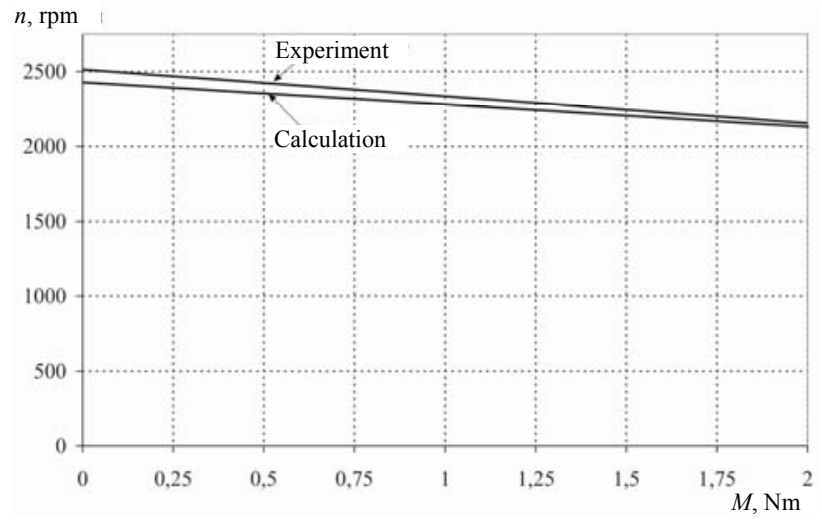

Fig. 8. BPMM «natural» mechanical characteristics

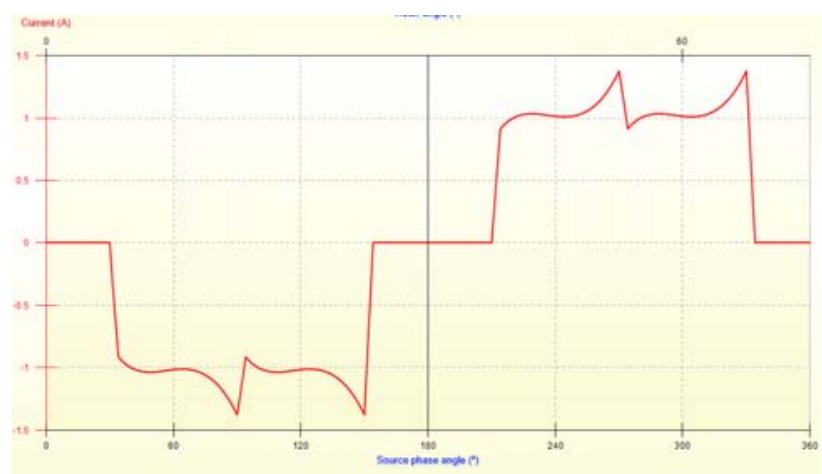

Fig. 9. Calculated oscillogram of the BPMM phase current at BPMM operation with load of $1 \mathrm{~N} \cdot \mathrm{m}$

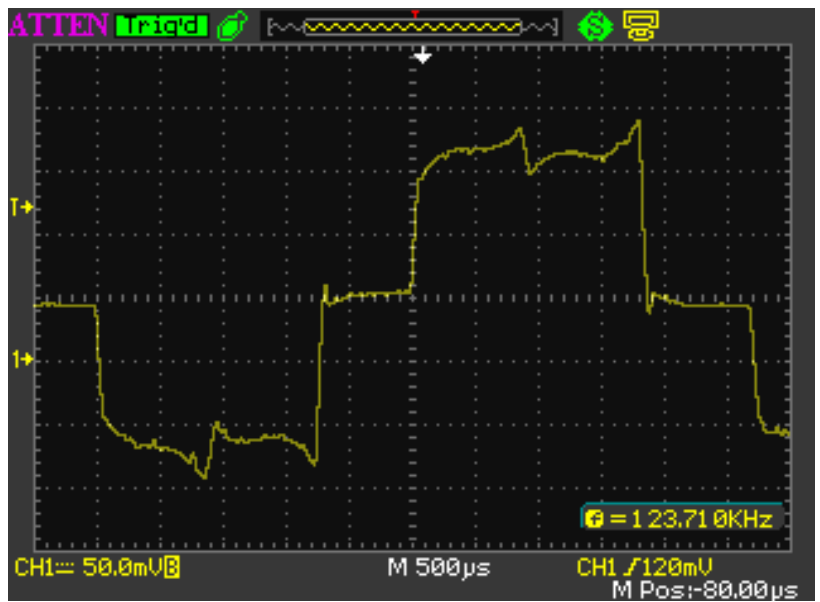

Fig. 10. Experimental oscillogram of the phase current at BPMM operation with load of $1 \mathrm{~N} \cdot \mathrm{m}$ 
Experimental oscillogram of the phase current was obtained using an ADS1062CM digital oscilloscope using a current sensor on a resistor with a resistance of $0.1 \Omega$. Scale on the experimental oscillogram: vertical -0.5 A/div., horizontal $-0.5 \mathrm{~ms} / \mathrm{div}$. In the experiment, the $\mathrm{BPMM}$ rotation frequency was $2330 \mathrm{rpm}$, and the average current value was $1.1 \mathrm{~A}$.

\section{Conclusions.}

1. Using the MotorSolve software package, the parameters and characteristics of the mass-produced BPMM were calculated. The calculation results have a slight difference from the data obtained experimentally, which confirms the high efficiency of the MotorSolve software package.

2. Unlike well-known codes for calculating the magnetic field, such as FEMM, the MotorSolve software package fully provides the calculation of parameters, transients and characteristics of the electric machine without the use of additional software.

\section{REFERENCES}

1. Available at: https://www.mentor.com/products/mechanical/ motorsolve/ (accessed 10 April 2019).

2. Grebenikov V.V. Comparison of characteristics of electric motors with permanent magnets with external and internal rotors. Hydropower Ukraine, 2018, no.3-4, pp. 46-50. (Rus).
3. Grebenikov V.V., Pryimak M.V. Comparative analysis of magnetic electric motors with permanent magnets for electric buses. Bulletin of NTU «KhPI». Series: "Electric machines and electromechanical energy conversion», 2016, no.11(1183). - pp. 42-48. (Rus).

4. Hendershot J.R., Miller T.J.E. Design of brushless permanent-magnet motors. Magna Physics Publishing and Clarendon Press, Oxford, 1994. 579 p.

Received 12.04.2019

V.V. Rymsha ${ }^{1}$, Doctor of Technical Science, Professor,

I.N. Radimov ${ }^{2}$, Candidate of Technical Science, Associate

Professor,

M.V. Gulyy ${ }^{2}$, Candidate of Technical Science,

I.V. Merkulov ${ }^{1}$, Senior Instructor,

${ }^{1}$ Odessa National Polytechnic University,

1, Shevchenko Avenue, Odessa, 65044, Ukraine,

phone +380487385855 ,

e-mail: rimsha61@gmail.com, miv080452@gmail.com

${ }^{2}$ Ltd. «Electrical Engineering - NewTechnology», 26/2, Melnitskaya Str., Odessa, 65005, Ukraine,

e-mail: igor.radimov@gmail.com, mv.skbss@gmail.com

How to cite this article:

Rymsha V.V., Radimov I.N., Gulyy M.V., Merkulov I.V. MotorSolve software package: verification of parameters and characteristics of the brushless permanent magnet motor. Electrical engineering \& electromechanics, 2019, no.5, pp. 20-24. doi: 10.20998/2074-272X.2019.5.03. 